Article

\title{
Analysis of Solid Waste Management Logistics and Its Attendant Challenges in Lagos Metropolis
}

\author{
Boye Benedict Ayantoyinbo * (1) and Olusegun Onifade Adepoju \\ Department of Transport Management, Faculty of Management Sciences, Ladoke Akintola University of \\ Technology, Ogbomoso, Nigeria; adeseg001@yahoo.com \\ * Correspondence: benedictboye@yahoo.com; Tel.: +234-80-3322-9046
}

Received: 10 April 2018; Accepted: 21 May 2018; Published: 11 June 2018

check for updates

\begin{abstract}
This study examined the relationship between waste management logistics and identified metrics for waste management logistics performance. Secondly, the study assessed the various challenges inhibiting the performance of LAWMA in the State. Random table sampling and purposive sampling were used to select 47 waste collection centres with 10 questionnaires distributed per centre (470 in total) across the 20 Local Government Areas (LGA) in Lagos State. However, only 339 questionnaires were retrieved from the sampled population. Multiple regression analysis was used to predict the relationship between waste management logistics and identified metrics for waste logistics performance. Descriptive statistics was used to explain the challenges of the Lagos State Waste Management Authority (LAWMA). The results established that the volume of solid waste and commitment of staff are crucial to waste management logistics and one factor that strongly affects waste logistics is traffic in the metropolis. Conclusively, waste collection turnaround must be increased and government and private investors should provide enabling infrastructure and trained personnel for effective solid waste management in Lagos metropolis.
\end{abstract}

Keywords: solid waste; logistics; challenges; Lagos metropolis

\section{Introduction}

Solid waste generation is a part of every human activity and each person in Nigeria generates at least $0.58 \mathrm{~kg}$ of solid waste per day [1]. According to the Federal Ministry of Environment [2], "as a result of industrialization and rapid population growths in many cities and towns, wastes are generated faster than they are collected, transported and disposed." Lagos metropolis is one of the fastest growing commercial cities in Nigeria and over the years has had problems with waste management logistics. With a per capita waste generation of $0.5 \mathrm{~kg}$ per day, the city generates more than 10,000 tons of urban waste every day [3]. To this end, the Lagos State government established the Lagos State Waste Management Authority (LAWMA). Girling [4] explained the historical development of waste management from the ancient days when human and animal excrement and stagnant water were everywhere. As the population increased and industrialization developed, the generation of waste became more rapid and its removal became difficult. Yoada et al. [5] noted in one of their articles that "The Sanitation Commission that was established in London in 1839 made the first clear linkages between infectious diseases such as cholera and poor sanitation conditions (though based on erroneous belief that disease is caused by 'miasma,' i.e., bad odour from decaying organic matter)". Based on the explanation of [6], it is evident that some of these wastes were dumped in streets, gutters, holes and nearby bushes. This had the potential of serving as breeding grounds for rodents and insects that could increase the spread of parasitic and zoonotic diseases. In the late 1980s, the Nigerian government introduced the War against Indiscipline (WAI) to inculcate orderliness and make Nigeria more environmentally friendly [7]. To that end, the timeliness of waste removal cannot 
be overemphasized. The achievement has been attributed to enforcement by the military administrator in Nigeria.

The transport systems are only pronounced on physical movement of goods among other related activities like inventory, storage/warehousing, among other components of supply chain management. MacArthur [8] noted that; as important as forward logistics, which influences global trade through transport of materials, goods and information from start to almost finish is reverse logistics (i.e., movement of the waste in this sense). Reverse logistics is 'the process of planning, implementing, and controlling the efficient, cost effective flow of raw materials, in-process inventory, finished goods and related information from the point of consumption to the point of origin for the purpose of recapturing value or proper disposal' [9].

In rapidly developing urban cities, where there is an influx of commercial, industrial and household activities, there used to be rapid generation of waste [2]. From the explanations of [5] and [10] people's perceptions about sanitation contribute to waste management practices. The challenges faced in Lagos metropolis in relation to waste management include inadequate availability of land, encroachment as a result of erecting structures where they are not supposed to be, space taken up by oceans and lagoons, inadequate transport facilities and improper usage of those available, and an unethical waste disposal culture, among others.

Lack of availability of funding for investment in waste management facilities is generally a constraint in cities in developing countries [11]. Achi et al. [12] explained that waste management problems stem from unsustainable methods of waste disposal and inadequate planning, which usually lead people to dump refuse on abandoned land, which can lead to pollution and health problems. Moreover, Lagos State lacks adequate space to accommodate waste disposal considering the daily influx of rural-urban migration, which is not commeasurable with the required expansion of the State's land mass. Bakare [3] noted that the fundamental issue is the delayed collection of household solid waste, with an example that, in some cases, waste is not collected for a week or two, so waste bins overflow and litter the surroundings. Achi et al. [12] identified that the problem with waste management is the inability to determine an appropriate route and proper allocation of refuse sites in Abeokuta, Ogun State Nigeria. From all the identified problems of waste management, transportation functionality has been seen as the most powerful tool that can alleviate its problems.

Most times, when vehicles are not available to convey waste away from locations, the waste would end up spread on the road or, when there was rainfall, erosion would carry the waste away. This can lead to redirection of traffic, block the drainage channels and, worse still, require extra energy and cost to re-gather the waste. Hence, the Lagos State Government created Lagos State Waste Management Authority (LAWMA) to address waste disposal problems in the State. Part of the reason for this is that waste causes pollution, traffic and human health problems. Aliu et al. [13] expressed that management of solid waste collection is the sole responsibility of the municipal government, the Lagos Waste Management Authority (LAWMA), established in 1991.

However, regulatory authority is vested in the Environmental Protection Agency (EPA) under the auspices of the Ministry of Environment [5]. The following questions can then be raised in order to investigate and analyse waste management logistics performance in Lagos metropolis:

- What are the combined and individual effects of the identified metrics on waste management logistics in Lagos metropolis?

- What are the factors inhibiting the performance of LAWMA in Lagos metropolis?

It was expected that, after the establishment of LAWMA and the involvement of various private organization in waste logistics management in Lagos State, there would be no delay between waste disposal and removal in the State. Federal Ministry of Environment [13] explained that there are 340 Private Sector Participants (PSPs) in Lagos State. In spite of this, there still exist problems relating to waste logistics in the metropolis. Therefore, this study investigated the causes with some identified metrics and challenges confronting the major government sector responsible for collection of waste in the metropolis. 


\section{Literature Review}

The movement of goods and services is crucial to the economy. Just as the removal of waste is important for the body's digestive system, so also is the evacuation of solid waste from our environment. Waste is presumed to be an unwanted or used material or product that must be disposed of by the consumer. Fantola [14] said that it can also be defined as any material flow pattern that is rejected by the society. Janusz and Mariana [15] defined logistic management of waste as the creation of logistic chains by the merging of waste disposal sites. However, solid waste management is [16] defined as the branch of solid waste engineering associated with the generation, storage, collection and transfer, transportation, processing and disposal of solid waste in a manner that is in accordance with the best principles of public health economics, engineering conservation, aesthetics and other environmental considerations. The challenges of waste management transport operators vary in terms of number of locations/distance or units to cover, number of trips to make, different kinds of waste to carry and type of vehicle to convey the waste.

Various techniques and methods are believed to be the solution to the problem of waste management and can be divided into two groups, viz. responsibility issues and public awareness [11]. Rogers and Tibben-Lembke [9] explained that there must be adequate knowledge of the quantity and characteristics of goods to be carried by transport operators like:

1. Method and frequency of pickup

2. Viability of transfer stations

3. Method of disposal to be selected (e.g., incineration, land filling, etc.)

4. Size and/or throughput capacity of the disposal facility required

This comprises sorting of waste, transport and storage, waste treatment and provision of secondary raw materials. This is perhaps why waste collection is the most difficult and expensive aspect of solid waste management [9]. Some of the challenges that usually confront the logistics of solid waste can be:

(1) No proper sorting to distinguish the garbage; (2) burning is not totally efficient; (3) injury sustained as a result of obscured sharp object in the garbage and (4) there is a possibility of inhaling hazardous chemicals.

\section{Conceptual Framework}

An increasingly important idea is waste prevention and recycling. In other words, it is believed that the more we prevent and recycle solid waste, the better off the environment will be. It is also hoped that there will be a seamless gap in waste management logistics turnaround as a result of less waste and lower cost. However, assessing this concept from a business perspective, Kopicki et al. [17] stressed that;

The value to be derived from the waste must be compared with the danger it may cause;

Purchase, storage, sorting, transformation, transport, processing, adaptation, recovery,

processing, storage and sale of removed materials are to be carefully considered;

There are other activities necessary to eliminate waste.

Recycling of waste is negligible, while the methods used for collection, transportation and final disposal are very unsatisfactory [2]. Aliu et al. [13] gave the procedures for waste management in Nigeria thus:

Waste storage $\rightarrow$ Waste collection $\rightarrow$ Collection equipment $\rightarrow$ Waste Transportation $\rightarrow$ Waste Station.

The Ministry explains that each household should have waste bins that can collect not less than $20 \mathrm{~kg}$ of waste, which must be covered and kept away from moisture and animals. The waste collection system should determine the number of locations for deposits, the number of personnel required, 
the vehicles and the route planning. Non-motorised vehicles like hand carts, animal-drawn carts, bicycles, etc. can be used as collection equipment as well as motorised transport for waste movement. The location of waste deposit centres should be known within a particular community.

The conceptual framework for the operational functionality of waste management logistics envisions a holistic transport demand management system with the aid of an information system. The process can be illustrated with the steps highlighted and the loop from the figure below:

(a) Identify and determine the waste locations;

(b) Strategically determine the number of vehicles and sizes required for each location;

(c) Understand the demand pattern through a pull and push system;

(d) Determine the waste deposit locations and required costs of operations;

(e) Prepare budgets to meet the expected costs of waste management and fleet management;

(f) Examine the performance of the logistical operation and feedback system.

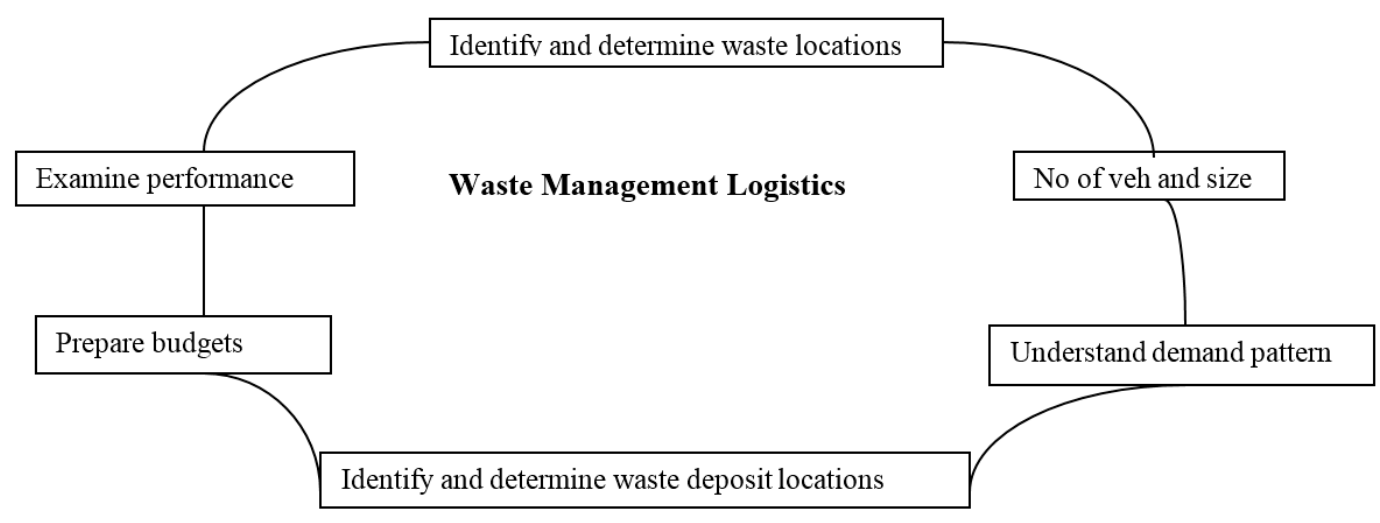

Figure 1. Waste management logistics system. Source: authors' design (2018).

Figure 1 presents a loop for waste management logistics. The identification and location of the waste bins for each geographical location can be carried out with the aid of a Geographic Information System. In other words, the spatial interactions within a certain community should be captured and analysed to determine suitable locations for the collection of waste. Secondly, the type of vehicle used and the size in each region are different based on collective waste activities within the locality. Thirdly, understanding the demand pattern is the most crucial part of waste management logistics. Here, transport demand system analysis must come in the form of predictive and prescriptive models. Predictive models could be deterministic or probabilistic. Deterministic models make accurate predictions about the system of interest, whereas probabilistic models entail some elements of uncertainty. The model can be illustrated by predicting the trip that will be generated from a zone using:

$$
\begin{gathered}
\mathrm{Y}=\mathrm{a}+\sum \mathrm{b}_{1} \mathrm{X}_{1}+\text { error } \\
\text { Where } \mathrm{Y}=\text { criterion variable } \\
\mathrm{A}=\text { the slope constant } \\
\mathrm{b}_{1-\mathrm{n}}=\text { partial regression coefficient } \\
\mathrm{X}_{1-\mathrm{n}}=\text { predictor variable }
\end{gathered}
$$

Predictive models are sometimes called planning or normative or optimizing models. They are concerned with what "ought to be" rather than "what is". Consequent to this, the accessibility and connectivity of the road network linking various waste deposit sites posed a serious problem to transport operators and government officials (LAWMA). There are places like Ijegun in Alimosho Local 
Government Area that tend to be inaccessible during the rainy season. According to $[13,18,19]$ there are various methods of solid waste collection, especially in Lagos: manual, semi-automated and fully automated. Manual can be operated by the driver, who loads and drives the vehicle; semi-automated requires the driver to operate the mechanical propeller of the vehicle to transfer the refuse into the body of the vehicle; the fully automatic method uses a compactor vehicle, which is a technologically advanced waste collection system designed to improve collection efficiency and performance.

Arbisala and Ikudayisi [16], when analysing the challenges of transportation of waste management logistics at the College of Education, Ikere Ekiti, noted that organic solid waste, especially when wet, usually takes up more space in the transportation vehicle than necessary. This may increase the number of journeys in a densely populated place like Lagos, raising concerns about traffic and fuel consumption. Due to the inadequacy of government vehicles, sometimes private operators provide transportation services for solid waste collection, given a certain fee. However, the challenges can usually be attributed to the usage of uncovered, closed-body vehicles that allow some of the waste to be dispersed in the wind. Ogra [20] maintained that determining transport routes for waste collection is essential to reduce travel costs and increase efficiency.

Urban waste collection involves large operational costs in terms of fleet management and maintenance, and the environmental costs of emissions, noise and traffic [21]. In all these activities, transportation costs account for $1 / 3$ of the total logistics cost [22]. In the case of waste management, the costs can be broken down into the cost of operating a suitable means of transport, loading and unloading costs, cargo handling costs and personnel costs [12].

Aliu et al. [13] opined that a Public-Private Partnership is a strategy that could enhance waste management logistics in Lagos State. A Geographic Information System (GIS) should be adopted in waste management logistics for the purpose of determining the most efficient and least costly route for transporting waste to landfills or recycling centres. Janusz and Mariana [15] described policy and enforcement as solutions to waste logistics problems in the city.

The work of [13] used 26 variables in three categories to assess waste management logistics.

First category: Service reliability variables, cost (affordability), payment flexibility, coverage, accessibility, consistency and tidiness of street.

Second category: Operational quality variables: The seven operational key indicators include number of vehicles, maintenance level, volume capacity of vehicle, trip rate, frequency of collection, number of personnel and quality of personnel.

Third category: Individual lifestyle variables: The gender, age, marital status (lifecycle), monthly income (economic status), occupation, education, household size and waste generated. Even though the research considered a lot of variables to determine the performance of waste logistics management, it does not consider traffic and pick-up time. Similarly, the performance of Public-Private Partners was considered, whereas this study used LAWMA across the selected Local Government Areas of Lagos State with the inclusion of metrics like pick-up time, traffic and volume of solid waste at the various collection centres to assess waste management logistics.

\section{Methodology}

\section{The Study Area}

Lagos is in Southwestern Nigeria, longitude $2^{\circ} 42^{\prime}-4^{\circ} 20^{\prime}$ E and latitude $6^{\circ} 22^{\prime}-6^{\circ} 42^{\prime} \mathrm{N}$ as indicated in Figure 2. It is surrounded by the Atlantic Ocean to the south and has $22 \%$ of its land taken up by water (e.g., creeks). Lagos is a megacity and the most populous in Nigeria. Lagos has 20 recognised Local Government Areas and 44 Local Community Development Areas (LCDAs) with the major seaports and airports in Nigeria. 


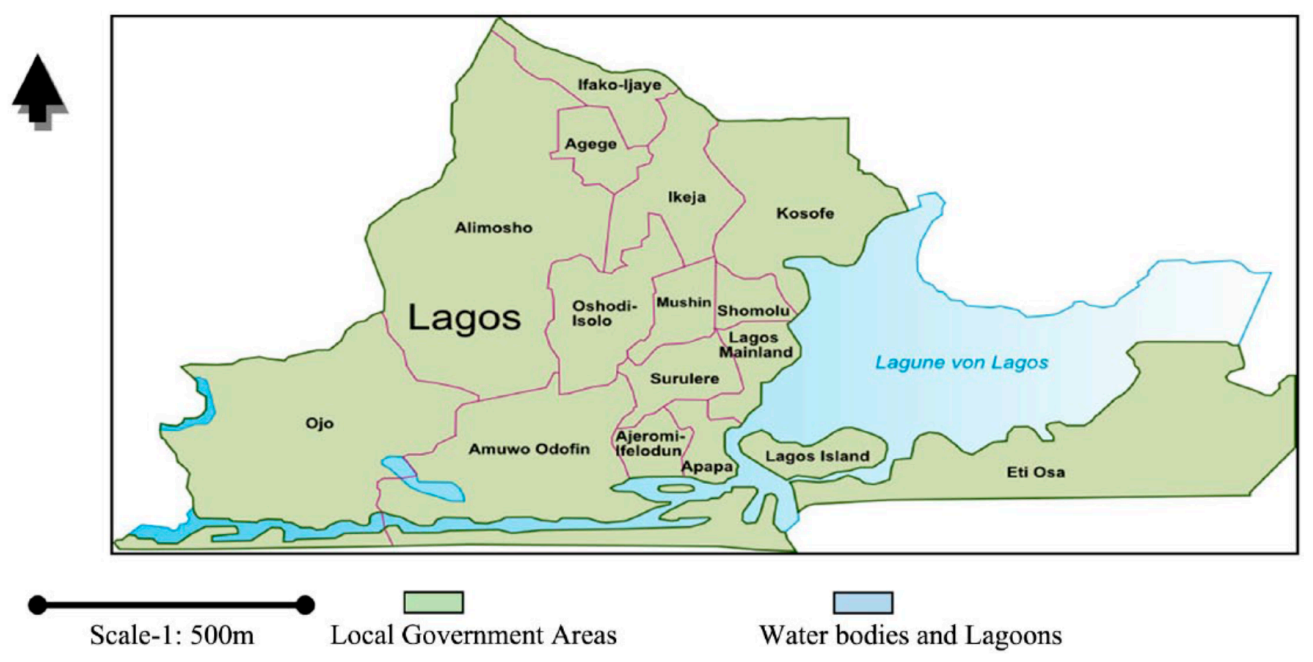

Figure 2. Map of Lagos metropolis. Source: Adapted [4].

A multistage sampling technique was used for this study. At stage one, the 20 Local Government Areas in Lagos State were stratified into three strata based on their senatorial districts. At the second stage, three Local Governments were randomly selected by balloting each of the Senatorial Districts. At the third stage, 47 waste collection centres across the randomly selected Local Government were purposively selected based on the volume of their waste deposit. At the fourth stage, 10 workers from each of 47 purposively selected waste collection centres were given questionnaires. However, only 339 responses were received back from the sampled population. The responses gathered were classified under the following variables of performance metrics for waste management in the state.

(a) Number of times the waste vehicle comes/week (frequency);

(b) Tonnage of waste (loading per trip);

(c) Volume of solid waste (weight in tonnage capacity of the vehicle);

(d) Volume of traffic (time required for movement; actual time used);

(e) Pick-up time (morning, afternoon or evening);

(f) Commitment of personnel to loading and offloading (loading time and offloading time).

\section{Results and Discussion}

The results of the inferential statistics are presented in Tables 1-3.

Using multiple regression: $Y i=b 0+b_{1} X_{i 1}+b_{2} X_{i 2}+\ldots+b_{n} X_{n P}+\varepsilon_{i}$

Table 1. Lagos State local government areas.

\begin{tabular}{ccc}
\hline S/N & LGA & Population \\
\hline 1 & Alimosho & $8,700,714$ \\
2 & Ajeromi-Ifelodun & 745,634 \\
3 & Kosofe & 665,998 \\
4 & Mushin & 633,543 \\
5 & Oshodi-Isolo & 621,789 \\
6 & Ojo & 598,332 \\
7 & Ikorodu & 535,811 \\
8 & Surulere & 504,408 \\
9 & Agege & 461,123 \\
10 & Ifako-Ijaye & 428,812 \\
11 & Shomolu & 402,992 \\
\hline
\end{tabular}


Table 1. Cont.

\begin{tabular}{ccc}
\hline S/N & LGA & Population \\
\hline 12 & Amuwo-Odofin & 318,576 \\
13 & Lago Mainland & 317,980 \\
14 & Ikeja & 313,333 \\
15 & Eti-Osa & 287,958 \\
16 & Badagry & 241,437 \\
17 & Apapa & 217,661 \\
18 & Lagos-Island & 209,665 \\
19 & Epe & 181,715 \\
20 & Ibeju-Lekki & 117,542 \\
\hline & Total & $40,013,534$ \\
\hline
\end{tabular}

[11], accessed 2018: http://www.naijaloaded.com.ng.

Table 2. Analysis of solid waste logistics performance model.

\begin{tabular}{|c|c|c|c|c|c|}
\hline Multiple R & & \multicolumn{4}{|c|}{0.901} \\
\hline R Square $\left(R^{2}\right)$ & & \multicolumn{4}{|c|}{0.811} \\
\hline Adjusted $R^{2}$ & & \multicolumn{4}{|c|}{0.808} \\
\hline Standard Erro & & \multicolumn{4}{|c|}{0.578} \\
\hline \multicolumn{6}{|c|}{ Analysis of Variance } \\
\hline & DF & Sum of Squares & Mean Square & F-ratio & Sig. \\
\hline Regression & 5 & 479.561 & 95.912 & & \\
\hline Residual & 333 & 111.625 & 0.335 & 286.127 & 0.000 \\
\hline
\end{tabular}

The research findings showed that the identified metrics of solid waste logistics have an influence on logistical performance. The $R$ value of 0.901 revealed the degree of relationship between the dependent variable and the combined independent variables. $R$ is a gauge of how well the model predicts the observed data. In other words, this means there is a high degree of correlation (about $90 \%$ ) between the performance of waste management logistics and identified variables (commitment, intensity of traffic, tonnage of loading, pick-uptime, volume of waste) combined. $R^{2}$ is the amount of variation in the outcome variable that is accounted for by the model. In this case, the model can only account for $81.1 \%$ of the independent variables in relation to the dependent variable. This means that about $18.9 \%$ of the variation in the dependent variable cannot be accounted for by the model or can be attributed to other factors. The adjusted $R$ shows the shrinkage, in which case, if the entire population was used, the model would have predicted $80.8 \%$.

Table 3. Coefficients of determinations.

\begin{tabular}{|c|c|c|c|c|c|}
\hline \multicolumn{6}{|c|}{ Coefficients $^{\text {a }}$} \\
\hline \multirow{2}{*}{ Model } & \multicolumn{2}{|c|}{ Unstandardized Coefficients } & \multirow{2}{*}{$\begin{array}{c}\text { Standardized Coefficients } \\
\text { Beta }\end{array}$} & \multirow{2}{*}{$\mathbf{t}$} & \multirow{2}{*}{ Sig. } \\
\hline & B & Std. Error & & & \\
\hline (Constant) & $-2.132 \times 10^{-5}$ & 0.123 & & 0.000 & 1.000 \\
\hline tonnage of loading & 0.014 & 0.033 & 0.012 & 0.443 & 0.658 \\
\hline Volume of waste & 0.571 & 0.073 & 0.561 & 7.788 & 0.000 \\
\hline intensity of traffic & -0.076 & 0.022 & -0.089 & -3.535 & 0.000 \\
\hline pick-uptime & 0.119 & 0.068 & 0.104 & 1.754 & 0.080 \\
\hline commitment & 0.298 & 0.037 & 0.309 & 8.174 & 0.000 \\
\hline
\end{tabular}

Furthermore, in Table 2, the most important values that need to be examined are the F-ratio and sig values. As the sig value shows 0.000 and $F=286.127$, then the F-ratio is acceptable because of the 
sig value $(p<0.05)$. The F-ratio is high, which is an indication that the model is a good prediction of the relationship between dependent and independent variables.

From Table 3, two variables are not statistically significant. These are tonnage of loading and pick-uptime, with sig values of 0.658 and 0.08 , respectively. This is because their respective sig values are more than the acceptable sig value of 0.05 . However, a unit increase in the size of the waste contributes about 0.571 to the logistical performance and a unit increase in traffic causes a decrease in the performance of waste logistics by 0.76 ; lastly, if there is a commitment from the operators by a unit, it leads to an increase in logistical performance by 0.298 .

The implications of these findings for both the body of knowledge and practitioners are:

(a) There should be a way to reduce solid waste deposits, perhaps by assigning community representatives based on cordon demarcation of the LGAs, whereby they can have the contact details for the waste collectors or vice versa for rapid evacuation of waste at different identified centres.

(b) The commitment of waste management logistics staff is important, so skilled personnel with a passion for the job are required.

(c) There is no way waste management logistics can be effective unless the traffic usually experienced daily in the metropolis is mitigated.

Summarizing the open-ended questions answered by the respondents in relation to the challenges of LAWMA's logistics, apie chart has been produced in Figure 3.

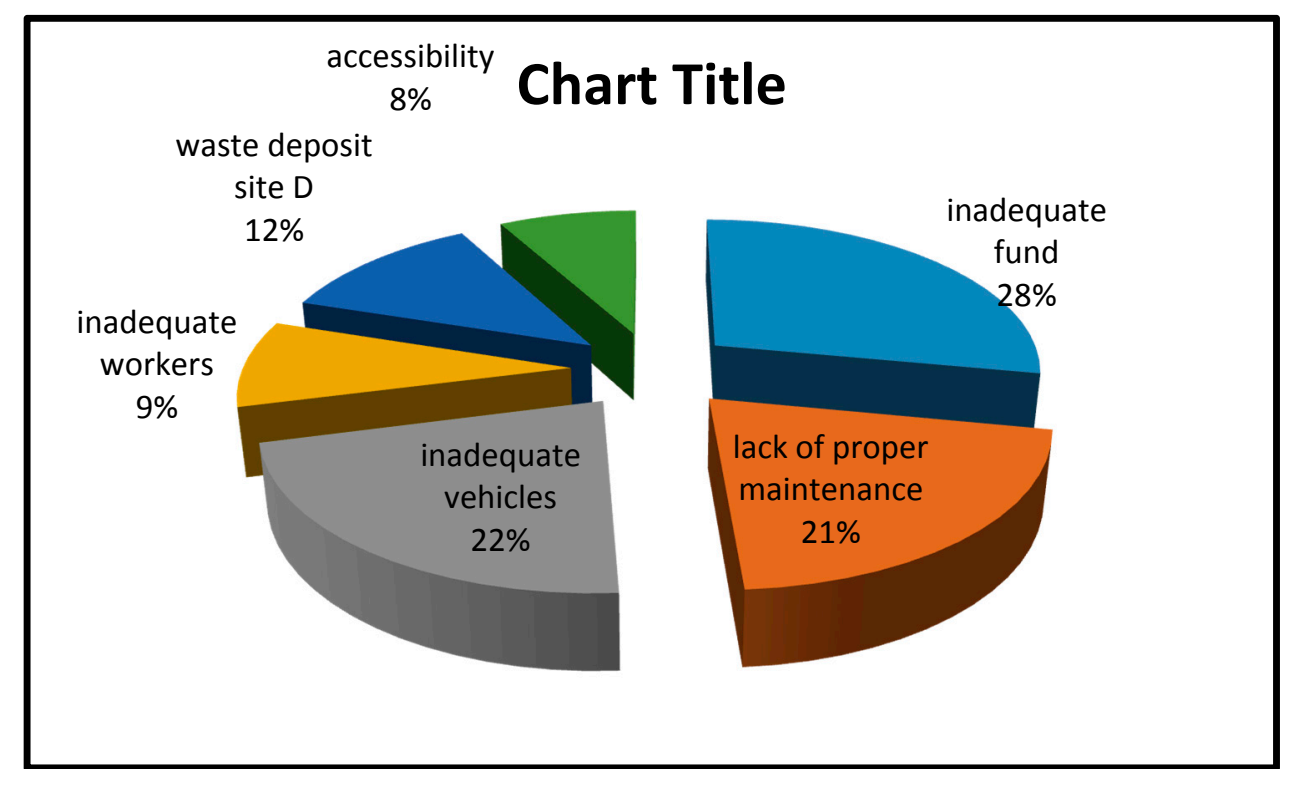

Figure 3. Challenges of LAWMA's logistics.

Figure 3 shows the various responses gathered on LAWMA's logistics challenges. Top of the list is inadequate funding with $28 \%$, followed by inadequacy of vehicles $(22 \%)$, which was followed closely by lack of proper maintenance of available vehicles. The majority of the respondents $(12 \%)$ also revealed that sometimes the distance from the different waste centres to the refuse site has been a major challenge. About $9 \%$ of the respondents claimed that the number of staff hired for the job is grossly inadequate. The last category $(8 \%)$ explained that some areas where the waste should be collected are inaccessible.

\section{Conclusions and Recommendations}

Obviously, from the findings of this research work, transportation plays a vital role in waste logistics in the study area. The rapid build-up of waste in the metropolis is a major factor to be 
considered. Moreover, the two possibilities for waste management logistics are either to allow the solid waste to reach a sizable volume before evacuation or to provide a rapid transport system for its removal. The difficulties in the later may be attributed to the costs of fuel, vehicle maintenance, wages, etc. To achieve a reliable system of waste management in Lagos requires committed, skilled personnel. In order to solve the traffic problem and achieve an environmentally friendly metropolis, the government should adhere to monthly or bi-monthly sanitation programmes to give room for collection of waste by the agencies and private investors concerned. The research, however, advocates for proper funding of the waste logistics system. The government can introduce a Public-Private Partnership (PPP) programme that can facilitate repairs and proper maintenance if the cost is too much to bear.

Author Contributions: O.O.A. conceptualized the research with the problems encountered in waste management in Lagos State while B.B.A. reworded and formulated the title. Author 1 provided the analysis and discussed the methodology while O.O.A. went with some people to collect data. Although B.B.A. analysed the data collected but, the editing and proof reading was carried out with mutual understanding by both authors. Both B.B.A. and O.O.A. edited and proof read the final article before submission and B.B.A. collaborated with O.O.A. for reviewers' reports and necessary corrections were made. This research work is sponsored by the authors. B.B.A.

Acknowledgments: We sincerely appreciate the Head of Department of Transport Management Department, LAUTECH for the permission he granted when we requested for field study vacation.

Conflicts of Interest: The authors declare no conflict of interest.

\section{References}

1. Adewumi, I.K.; Ogedengbe, M.O.; Adepetu, J.A.; Fabiyi, Y.L. Planning Organic Fertilizer Industries for Municipal Solid Wastes Management. J. Appl. Sci. Res. 2005, 1, 285-291.

2. Federal Ministry of Environment. Policy Guidelines on Solid Waste Management; Federal Ministry of Environment: Mabushi, Nigeria, 2005.

3. Bakare, W. Solid Waste Management in Nigeria. Available online: https://www.bioenergyconsult.com/ solid-waste-nigeria/ (accessed on 22 May 2018).

4. Girling, R. Rubbish! Dirt on Our Hands and the Crisis Ahead; Eden Project Books; Random House: London, UK, 2005.

5. Yoada, R.M.; Chirawurah, D.; Adongo, P.B. Domestic waste disposal practice and perceptions of private sector waste management in urban Accra. BMC Public Health 2014, 14, 697. [CrossRef] [PubMed]

6. Abeyewickreme, W.; Wickremasinghe, A.R.; Karunatilake, K.; Sommerfeld, J.; Axel, K. Community mobilization and household level waste management for dengue vector control in Gampaha district of Sri Lanka; An intervention study. Pathog. Glob. Health 2012, 106, 479. [CrossRef] [PubMed]

7. Okafor, D. The Cacophonous Terrain of Nigerian/African Literature. In Meditation on African Literature; Okafor, D., Ed.; West Port, Conn.: London, UK; Greenwood Press: Westport, CT, USA, 2010; pp. 1-16.

8. MacArthur, E. Foundation "Towards the Circular Economy -Economic and Business Rationale for an Accelerated Transition" 2013; European Environment Agency “Circular Economy in Europe”: Copenhagen, Denmark, 2016.

9. Rogers, D.S.; Tibben-Lembke, R.S. Going Backwards: Reverse Logistics Trends and Practices; The University of Nevada: Reno, NV, USA, 1998.

10. Banjo, A.D.; Adebambo, A.R.; Haight, M. Inhabitants' Perception on Domestic Waste Disposal in Ijebu Ode, Southwest Nigeria; Department of Biological Sciences; Tai Solarin University of Education: Ijebu Ode, Nigeria, 2009.

11. Wilson, D.C. Directions in Waste Management-Past, Present and Future. In International Directory of Solid Waste Management 1999/2000 - The ISWA Yearbook; James \& James: London, UK, 1999.

12. Achi, H.A.; Adeofun, C.O.; Ufoegbune, G.C.; Gbadebo, A.M.; Oyedepo, J.A. Disposal Sites and Transport Route Selection Using Geographic Information System and Remote Sensing in Abeokuta, Nigeria. Glob. J. Hum. Soc. Sci. Geogr. Environ. GeoSci. 2012, 12. Available online: https://socialscienceresearch.org/index. $\mathrm{php} / \mathrm{GJHSS} /$ article/view/445/396 (accessed on 8 June 2018).

13. Aliu, I.R.; Adeyemi, O.E.; Adebayo, A. Municipal household solid waste collection strategies in an African megacity: Analysis of public private partnership performance in Lagos. Waste Manag. Res. 2014, 32, 67-78. [CrossRef] [PubMed]

14. Fantola, A. Introduction to Solid Waste Management Engineering; Bibis Press: Ibadan, Nigeria, 1997; pp. 25-30. 
15. Janusz, G.; Mariana, M. Assessment of Logistic Outlays in Industrial Solid Waste Management. Soc. Sci. Educ. Res. Rev. 2014, 1, 11-21.

16. Arbisala, G.; Ikudayisi, A.M. Assessment of solid waste management problems in College of Education, Ikere-Ekiti, Ekiti State, South West Nigeria. Sch. J. Educ. 2012, 1, 42-45.

17. Kopicki, R.; Berg, M.J.; Legg, L. Reuse and Recycling-Reverse Logistics Opportunities; Council of Logistics Management: Oak Brook, IL, USA, 1993.

18. Agunwamba, J.C. Solid waste management in Nigeria: Problems and issues. J. Environ. Manag. 1998, 22, 849-856. [CrossRef]

19. Balogun, Y.O.; Odumosu, J.O.; Ojo, A.O. Lagos in Maps; Rex Charles: Lagos, Nigeria, 1999.

20. Ogra, A. Logistic Management and Spatial Planning for Solid Waste Management Systems using Geographical Information System. Map Asia 2004, 13, 60-65.

21. Faccio, M.; Persona, A.; Zanin, G. Waste collection multi objective model with real time traceability data. Waste Manag. 2011, 31, 2391-2405. [CrossRef] [PubMed]

22. Tseng, Y.-Y.; Taylor, M.; Yue, W.L. The Role of Transportation in Logistics Chain. Proc. East. Asia Soc. Trans. Stud. 2005, 5, 1657-1672.

(C) 2018 by the authors. Licensee MDPI, Basel, Switzerland. This article is an open access article distributed under the terms and conditions of the Creative Commons Attribution (CC BY) license (http:/ / creativecommons.org/licenses/by/4.0/). 